\title{
Introduction to the special issue on new advances on stratigraphy and paleontology in Taiwan
}

\author{
Jih-Pai Lin ${ }^{1, *}$, Chien-Hsiang Lin ${ }^{2}$, Wei-Chia Chu ${ }^{3}$, and Chun-Hsiang Chang ${ }^{4}$ \\ ${ }^{1}$ Department of Geosciences, National Taiwan University, Taipei City, Taiwan \\ ${ }^{2}$ Biodiversity Research Center, Academia Sinica, Taipei City, Taiwan \\ ${ }^{3}$ Central Geological Survey, MOEA, Taipei City, Taiwan \\ ${ }^{4}$ National Museum of Natural Science, Taichung City, Taiwan
}

\section{Article history:}

Received 25 December 2021

Accepted 29 December 2021

Keywords:

Fossils, Cenozoic geology, taxonomy, paleobotany, paleoecology,

Echinodermata

Citation:

Lin, J.-P., C.-H. Lin, W.-C. Chu, and C.-H. Chang, 2021: Introduction to the special issue on new advances on stratigraphy and paleontology in Taiwan. Terr. Atmos. Ocean. Sci., 32, 1047-1050, doi: 10.3319/ TAO.2021.12.29.01

\begin{abstract}
Despite the long tradition of studies, there are excellent potentials for research in Taiwan due to emerging techniques and innovative approaches. On the other hand, breakthroughs in DNA sequencing technology have revolutionized our life, and paleontologists can also benefit from the interdisciplinary cooperation to shed light on the phylogeny and development of fossil species through investigating extant sister species. Moreover, unstudied new fossils have been collected and accumulated over the years in Taiwan. New studies attaining higher resolution on the spatiotemporal dynamics of past faunas have provided insights into past biodiversity patterns. In this special issue, a new fossil wood from Taiwan is officially named. The oldest known fossil coral from Taiwan is reported. New fossil records of Sinaechinocyamus mai (Wang 1984) are documented. Phylogenomics of living sand dollars (Echinodermata; Echinoidea) based on transcriptome with the inclusion of S. mai is discussed. Stereomic microstructures of the first Taiwan fossil echinoid Scaphechinus mirabilis A. Agassiz 1864 are illustrated. Incomplete keyholed sand dollars can be distinguished at the generic level based on landmark analyses. Morphometrics provides a new approach to explain the circular outlines that were achieved independently in distantly related lineages of sand dollars. Non-boring type fossil pholadid bivalves buried in situ from Taiwan is documented here for the first time.
\end{abstract}

\section{INTRODUCTION}

The field of stratigraphy and paleontology is fundamental to geosciences in general. Despite the long tradition of studies, there are excellent potentials for research in Taiwan due to emerging techniques and innovative approaches. Moreover, unstudied new fossils have been collected and accumulated over the years in Taiwan. New studies attaining higher resolution on the spatiotemporal dynamics of past faunas have provided insights into past biodiversity patterns. The aim is to show the diversity of research topics that are important for understanding the Earth History and biosphere in the past, particularly in the less known tropicalsubtropical West Pacific.

After the Young Paleontologist Forum 2020 meeting on 15 March and the Stratigraphy and Paleontology session

\footnotetext{
* Corresponding author

E-mail:alexjplin@ntu.edu.tw
}

(ST1) in the Geosciences 2020: New Horizon and Beyond from 17 to 18 November 2020, participants decided to call for papers summarizing their current works. Thus, a proposal of special issue titled "New advances on stratigraphy and paleontology in Taiwan" was submitted to the journal TAO office in December of 2020 and was approved by the TAO Editor-in-Chief Chung-Hsiung Sui. Among solicited provisional titles, eight papers are recommended for publication. Highlights of this special issue, covering topics such as paleobotany, coral biodiversity, sand dollar fossil records, phylogenomics, stereom, lunule, morphometrics, and bivalves buried in situ, are included below.

\subsection{A New Species of Fossil Wood}

The diversity and endemism of extant conifer genera in Taiwan are quite high, but there are only a few fossil conifer 
records reported in Taiwan, especially in macrofossils. This study by Lo and $\mathrm{Hu}$ (2021) described a new species Podocarpoxylon nageioides $\mathrm{Lo}$ and $\mathrm{Hu}, s p$. nov. from the Miocene strata in northern Taiwan. This study is the first record of Podocarpaceae macrofossil in Taiwan. The discovery of fossil wood provides a new reference for research in biogeography and fossil plant in Taiwan. According to anatomical features and the extant biogeographic distribution of Podocarpaceae, this fossil evidence also suggests a warm climate condition in northern Taiwan during the Miocene.

\subsection{Oldest Known Fossil Coral}

Contrary to the well-represented Pleistocene and Holocene uplifted corals, knowledge of Neogene coral diversity is extremely limited in Taiwan. However, numerous Dendrophyllia specimens from late Miocene (8 Ma) sites along the Dahan River in Shulin, New Taipei City, were reported by Ribas-Deulofeu et al. (2021) in this issue. The finding is regarded as one of the earliest coral records in Taiwan. Along with other marine fossils and associated sedimentary environments (Lin et al. 2021a; Lin and Chien 2022), the authors interpreted a local shallow, murky marine paleoenvironment.

\subsection{Fossil Records of Sinaechinocyamus}

Sinaechinocyamus Liao 1979 is a sand dollar genus with an excellent fossil record in Taiwan. In addition, the extant species Sinaechinocyamus mai (Wang 1984) is named in memory of Ting-Ying H. Ma (1899 - 1979) who is a famous geologist and paleontologist (Yang and Oldroyd 2003). The extant distribution of $S$. mai extends from Hsinchu to Tainan in the coastal intertidal zone of western Taiwan. However, the classification of the fossil Sinaechinocyamus in Taiwan remains unresolved. Chu and Chang (2021) analyzed the stratigraphy and morphology parameters of Sinaechinocyamus spp. specimens from nine sites. According to the stratigraphic occurrences, Sinaechinocyamus first appeared in the northern part of Taiwan since the late Miocene and gradually migrated to southern Taiwan during the late Pliocene. The principal component analysis suggests that the fossil Sinaechinocyamus spp. collected from four fossil localities fall within the morphology dimensions of extant S. mai.

\subsection{Molecular Phylogeny of Sand Dollars}

In the last decade, breakthroughs in DNA sequencing technology have revolutionized the life science field. Paleontologists can also benefit from the interdisciplinary cooperation to shed light on the phylogeny and development of fossil species through investigating extant sister species. The phylogeny of irregular echinoids derived from previous molecular evidence contradicts morphology-based one. In this study, Chang et al. (2021) sequenced the transcriptome of Sinaechinocyamus mai, an endemic Taiwanese sand dollar species, and subsequently incorporated transcriptomebased phylogenomic analysis. The result indicates that Scaphechinus mirabilis A. Agassiz 1864 is the sister group to $S$. mai, consistent with morphological analysis. On the other hand, the analysis also reveals that the traditionally viewed monophyletic order Clypeasteroida is a paraphyletic group, and the suborder Scutellina should be elevated to an independent order Scutelloida in congruence with the analysis of Mongiardino Koch and Thompson (2021).

\subsection{Stereom Study}

Echinoderm ossicles consist of stereomic microstructures known as stereoms (translated as "Jing-gu" in Chinese; Lin 2018). They are fundamental building blocks and are crucial for determining echinoderm affinity for some Cambrian taxa (Lin et al. 2008). In the paper by Lin et al. (2021b), they have examined 1543 fossil specimens and made 86 thin sections for studying the preservation of stereomic microstructure, or stereom, of Scaphechinus mirabilis A. Agassiz 1864 from Taiwan. This species has abundant fossil occurrences in northern Taiwan (Hayasaka and Morishita 1947; Morishita 1967; Wang et al. 1984), but no living record is documented. Thin-section study shows that stereoms are well preserved and at least four stereom types (labyrinthic, rectilinear, fascicular, and galleried) from Taiwanese echinoderms are documented for the first time. In addition, the growth patterns of marginal plates with stereoms in ontogenetic series are illustrated and discussed. A complete longitudinal section with periproct is illustrated in the center of the cover for this special issue. Lastly, threedimensional rendering via Delta $\mu \mathrm{CT}-100 \mathrm{X}$ provides a nondestructive approach to visualize the stereom.

\subsection{Incomplete Specimens of Astriclypeus}

Paper by Sankar and Swisher (2021) focuses on two important limitations in paleontology: (1) the availability of often incomplete specimens, and (2) restricted access/collecting of specimens. The authors provide a solution in their case study. Yehliu Geopark located in the northeast coast of Taiwan is a very popular national park; thus, it is very difficult to obtain a permit to collect fossil specimens. Exposed strata are mainly Taliao Formation (early Miocene) that are rich in fossil sand dollars (Echinoidea) with lunules. There are two genera of keyhole echinoids present in the park. Astriclypeus contains five lunules and Echinodiscus bears two lunules. Due to incomplete preservation sometimes it is difficult to distinguish them apart. This study both performed on-site measurements of the lunule shape and ratio and photographed fossils in the field and analysed the data in the lab with Principal Component Analysis. Their work yielded 
promising results to distinguish the two genera based on incomplete specimens.

\subsection{Morphometrics Study of Sand Dollars}

One of the most fascinating aspects of Clypeasteroids is the amount of morphological variation that has been achieved in a relatively short amount of evolutionary time. Clypeasteroids have obtained a wide variety of shapes including triangular outlines, outlines with posterior digits, more elongate morphologies, pentagonal outlines, morphologies raised in posterior profile, and, of interest for this analysis, distinctive circular outlines. To approach the question of understanding how circular morphologies were obtained within clypeasteroids Swisher (2021) employs geometric morphometric analyses to assess and compare morphological variation within the study group genera Dendraster and Arachnoides, two clypeasteroids with these distinctive circular outlines.

\subsection{Fossil Bivalves Buried In Situ}

Fossil bivalve is one of the most common large invertebrate fossils found in Taiwan (Hu 1995; and references therein). Although ichnofossils are commonly preserved in situ, report of invertebrate body fossils buried in situ in Taiwan is scarce (Wang 1985). Shell beds generally are composed of transported bivalve shells in aggregates. Specimens of Miocene pholadid bivalves reported in Lin et al. (2021c) are different, however, they are preserved with both valves intact. Furthermore, they are found oriented with the long axis perpendicular to the bedding plane. This is the first report for non-boring type pholadid bivalves buried in situ in Taiwan. It provides new information about the substrate conditions, water quality, ecology, association with other infaunal organisms, and sedimentation rate at the time of deposition of the fossil-bearing unit.

Despite the influence of COVID-19 pandemic worldwide, Taiwan palaeontologists find ways to be connected and to network with international colleagues through online conferences. During the submission stage for the special issue, we proposed a theme section with the same title for the third Palaeontological Virtual Congress (http://palaeovc.org/index.php/2022/01/08/results-3rd-edition-december-2021/) held from the $1^{\text {st }}$ to $15^{\text {th }}$ of December, 2021. Among 280 abstracts and three virtual field trips published, our session contains 16 abstracts with topics covering CT scanning, mammoths, stable isotopes, clumped isotopes, AMS carbon dating, sand dollars, fish otoliths, sharks, drill holes and prey-predator interactions, dinosaur eggshells, fossil earthquakes, geometric morphometrics and Quaternary climate change in addition to two virtual field trips showcasing some wonderful geology and fossil hunting sites in Taiwan.
As outlined in Shieh (2018), there are still a lot of works on stratigraphy and paleontology of Taiwan needed to be done. With the publication of this special issue, it represents the first issue in an SCI-indexed journal highlighting the Taiwanese fossil studies conducted by a younger generation of workers in the field of paleontology/paleobiology. With the open access policy, we can share our studies with global audiences via social media immediately after the official release online. We hope it will inspire more students to pursue paleontology as a career.

Acknowledgements We dedicate this special issue to professor Ting-Ying H. Ma (1899 - 1979) who served as the first department chair of the Department of Geology of National Taiwan University. We thank Kae-Shyuan Shieh who organized Taiwanese paleontologists and called for a special issue in the journal Ti-Chih in 2018. JPL thank WenShan Chen for sharing his knowledge in the field. Studies presented here cannot be completed without the continuous financial support from the Ministry of Science and Technology. We thank all the authors and the reviewers for making this special issue possible. Finally, we would like to thank the Editor-in-Chief Li-Hung Lin, the Geology section editor Yuan-Hsi Lee and supporting staff members of Terrestrial, Atmospheric and Oceanic Sciences (TAO).

\section{REFERENCES}

Chang, L.-Y., S.-J. Lee, M.-H. Tsai, and J.-P. Lin, 2021: Review of clypeasteroids phylogeny and a case study of Sinaechinocyamus mai (Taiwanasteridae). Terr. Atmos. Ocean. Sci., 32, 1081-1092, doi: 10.3319/ TAO.2021.10.01.01. [Link]

Chu, W.-C. and L.-Y. Chang, 2021: Restudy of fossil specimens of Sinaechinocyamus (Echinoidea; Scutelloida) with new occurrences from Taiwan. Terr. Atmos. Ocean. Sci., 32, 1069-1080, doi: 10.3319/ TAO.2021.12.21.01. [Link]

Hayasaka, I. and A. Morishita, 1947: Notes on some fossil echinoids of Taiwan, II. Acta Geol. Taiwan., 1, 93-109.

Hu, C. H., 1995: Mollusc fossils throughout Taiwan island (part 2). Taiwan Fossil Mollusk Fauna, National Museum of Natural Science, 1927-2166.

Lin, C.-H. and C.-W. Chien, 2022: Late Miocene otoliths from northern Taiwan: Insights into the rarely known Neogene coastal fish community of the subtropical northwest Pacific. Hist. Biol., 34, 361-382, doi: 10.1080/08912963.2021.1916012. [Link]

Lin, C.-H., C.-W. Chien, S.-W. Lee, and C.-W. Chang, 2021a: Fish fossils of Taiwan: A review and prospection. Hist. Biol., 33, 1362-1372, doi: 10.1080/08912963.2019.1698563. [Link]

Lin, J.-P., 2018: Introduction to fossil echinoids. Ti-Chih, 37, 22-27. (in Chinese) 
Lin, J.-P., W. I. Ausich, Y.-L. Zhao, and J. Peng, 2008: Taphonomy, palaeoecological implications, and colouration of Cambrian gogiid echinoderms from Guizhou Province, China. Geol. Mag., 145, 17-36, doi: 10.1017/S0016756807003901. [Link]

Lin, Y.-J., J.-N. Fang, C.-C. Chang, C.-C. Cheng, and J.-P. Lin, 2021b: Stereomic microstructure of Clypeasteroida in thin section based on new material from Pleistocene strata in Taiwan. Terr. Atmos. Ocean. Sci., 32, 1093-1105, doi: 10.3319/TAO.2021.07.28.01. [Link]

Lin, Y.-J., J.-Y. Lin, and L.-C. Wu, 2021c: In situ preservation of "Pholas tzayi Hu, 1992" (Mollusca, Pholadidae) from Chinshui Shale (Pliocene) in western Taiwan. Terr. Atmos. Ocean. Sci., 32, 1131-1140, doi: 10.3319/TAO.2021.12.15.01. [Link]

Lo, Y.-P. and J.-M. Hu, 2021: A new record of Podocarpaceae fossil wood from Miocene strata, Northern Taiwan. Terr. Atmos. Ocean. Sci., 32, 1051-1059, doi: 10.3319/TAO.2021.07.28.02. [Link]

Mongiardino Koch, N. and J. R. Thompson, 2021: A totalevidence dated phylogeny of Echinoidea combining phylogenomic and paleontological data. Syst.Biol., 70, 421-439, doi: 10.1093/sysbio/syaa069. [Link]

Morishita, A., 1967: On the measurements of Scaphechinus mirabilis (preliminary report). Contributions to Celebrate Prof. Ichiro Hayasaka's 76th Birthday, 109-116.

Ribas-Deulofeu, L., Y.-C. Wang, and C.-H. Lin, 2021: First record of Late Miocene Dendrophyllia de Blainville, 1830 (Scleractinia: Dendrophylliidae) in Taiwan. Terr. Atmos. Ocean. Sci., 32, 1061-1068, doi: 10.3319/ TAO.2021.09.13.02. [Link]

Sankar, A. and R. Swisher, 2021: Generic-level identification of Astriclypeidae based on incomplete onsite-specimens from Yehliu Geopark, Taiwan. Terr. Atmos. Ocean. Sci., 32, 1107-1115, doi: 10.3319/ TAO.2021.12.15.03. [Link]

Shieh, K.-S., 2018: Fossils and their implications. Ti-Chih, 37, 18-21. (in Chinese)

Swisher,R.E., 2021: Convergent discoidal sand dollars from isolated regions: A geometric morphometric analyses of Dendraster and Arachnoides. Terr. Atmos. Ocean. Sci., 32, 1117-1130, doi: 10.3319/TAO.2021.10.19.02. [Link]

Wang, C.-C., 1985: Application of fossils in field geology: Some examples. Annual Report of Central Geological Survey, 57-60.

Wang, C.-C., C.-F. Lin, and L.-C. Li, 1984: Measurements on Late Pleistocene sand dollar Scaphechinus mirabilis from northern Taiwan. Annual Report of Central Geological Survey, 49-56. (in Chinese)

Yang, J. Y. and D. Oldroyd, 2003: A Chinese palaeontologist, Ma Ting Ying (1899-1979): From coral growthrings to global tectonics. Episodes, 26, 19-25, doi: 10.18814/epiiugs/2003/v26i1/004. [Link] 